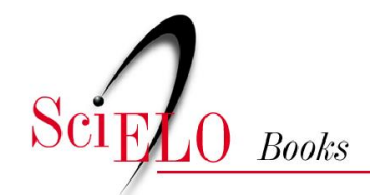

\title{
A interface da responsabilidade social na gestão de recursos naturais
}

\author{
José Mancinelli Lêdo do Nascimento \\ Rosires Catão Curi
}

\section{SciELO Books / SciELO Livros / SciELO Libros}

NASCIMENTO, JML., and CURI, RC. A interface da responsabilidade social na gestão de recursos naturais. In: LIRA, WS., and CÂNDIDO, GA., orgs. Gestão sustentável dos recursos naturais: uma abordagem participativa [online]. Campina Grande: EDUEPB, 2013, pp. 173-192. ISBN

9788578792824. Available from SciELO Books $<$ http://books.scielo.org $>$

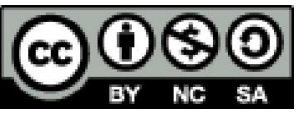

All the contents of this work, except where otherwise noted, is licensed under a Creative Commons Attribution-Non Commercial-ShareAlike 3.0 Unported.

Todo o conteúdo deste trabalho, exceto quando houver ressalva, é publicado sob a licença Creative Commons Atribuição Uso Não Comercial - Partilha nos Mesmos Termos 3.0 Não adaptada.

Todo el contenido de esta obra, excepto donde se indique lo contrario, está bajo licencia de la licencia Creative Commons Reconocimento-NoComercial-CompartirIgual 3.0 Unported. 


\title{
A interface da responsabilidade social na gestão de recursos naturais
}

\author{
José Mancinelli Lêdo do Nascimento \\ Rosires Catão Curi
}

\section{Introdução}

Em todo mundo, as organizações têm sido impulsionadas a buscar melhorias contínuas em seu desempenho. Estas ações são consequência da forma rápida e intensa das mudanças que impactam a sociedade e inquietam grande parte dos pesquisadores que aspiram prever cenários futuros das questões ambientais e sociais e, assim, monitorar as variáveis que podem ameaçar a biodiversidade. Torna-se, portanto, imperativo que o conjunto da sociedade civil organizada e as organizações públicas e privadas adotem uma nova postura quanto ao seu envolvimento e condução do meio ambiente no qual estão inseridos.

A reflexão sobre o meio ambiente perpassa pela necessidade de uma abordagem holística e um método interdisciplinar que permitam a integração das ciências da natureza e da sociedade, concentrando suas atenções na conservação dos recursos naturais e preservação da biodiversidade, em uma perspectiva do ideal material, econômico, tecnológico e cultural.

Para enfrentar as demandas dessa nova abordagem reflexiva sobre o meio ambiente, as organizações precisam de novos métodos gerenciais que assegurem a percepção da relevância de sua função social pela sociedade. A inclusão de práticas relacionadas à responsabilidade social conduz a organização a uma nova abordagem da gestão no que se refere ao alcance do sucesso comercial, mas honrando os valores 
éticos, respeitando as pessoas, comunidades e meio ambiente natural (BUSINESS..., 2006, p.6).

Nessa perspectiva, a aplicação dos conceitos referentes à responsabilidade social conduz a organização a uma nova abordagem de gestão, estabelecendo relações a partir de valores e condutas, como também, sendo capaz de satisfazer necessidades e interesses dos seus parceiros. Desta forma, o que se espera de uma organização realmente preocupada na solução dos problemas da sociedade, é a responsabilidade social como uma política institucional que envolva e comprometa todos os atores sociais da organização.

Segundo Egri e Pinfield (1998, p.384), “As atividades organizacionais não são independentes dos sistemas (...). Elas também absorvem recursos e suprimentos, que são transformados, para gerarem produtos (outputs) para o ambiente social maior”. As organizações vivem e operam no meio ambiente, do qual recebem insumos na entrada e colocam seus produtos na saída, através de bens, serviços e informações.

Para Ashley (2003, p.29), os objetivos empresariais transcenderiam os aspectos mensuráveis de emprego de fatores de produção, passando por uma forma de organização que conciliasse os interesses do individuo, da sociedade e da natureza, transitando do paradigma antropocêntrico, no qual a empresa é o centro de tudo, para o ecocêntrico; no qual, o meio ambiente é o mais importante, e a empresa, assim como outros agentes, insere-se nele.

E nessa visão ecocêntrica, estabelecer diretrizes de longo prazo para a gestão de recursos naturais requer a construção de modelos sistêmicos que permitam visualizar a relevância da mudança na percepção e no comportamento dos atores sociais, visando a uma nova ordem de interações. Essas diretrizes devem conter as definições de práticas de gestão que possam garantir os resultados esperados pelos atores sociais envolvidos no processo e que preservem os recursos naturais. Devem ser ancoradas na análise das condições externas, materiais e sociais, e do exercício da atividade econômica, além dos dispositivos institucionais que norteiam a sociedade.

Para Godard, (2002, p.209), “a promoção de uma gestão integrada de recursos naturais e do meio ambiente pode nos levar não só ao questionamento de certas modalidades técnicas de exploração, mas também estimular a busca de transformações das condições sociais que cercam seu exercício”. 
Propõe-se, então, neste estudo, um ensaio teórico que objetiva evidenciar a interface da responsabilidade social na gestão de recursos naturais tomando como referencial o modelo compacto de análise GREEN, adaptado por Vieira e Weber, $(2002,31)$ e as abordagens de (CARROL, 1991; ASHLEY, 2003) considerando: que o funcionamento de um sistema de gestão, na sua efetividade e eficiência, depende de como os atores sociais e organizacionais incorporam valores morais e éticos; o papel relevante das organizações públicas, privadas e informais como fonte aglutinadora de pessoas para solução de problemas; a inclusão de novos métodos gerenciais em busca da melhoria da qualidade da gestão.

$\mathrm{Na}$ estrutura proposta para este ensaio, inicialmente se faz um breve relato sobre organização e gestão, seguido de algumas considerações sobre responsabilidade social e finalmente procura-se estabelecer a interface entre responsabilidade social e a gestão de recursos naturais.

\section{Revisão de Literatura}

\section{Modelo GREEN no contexto da gestão}

Ao longo do tempo, as organizações foram sistematicamente incorporando novos valores culturais e aperfeiçoando as normas administrativas, forma de poder e de decisão sem maiores preocupações com as questões ambientais. No contexto atual, qualquer tipo de organização, seja do segmento privado, de arranjos estatais ou não governamentais, que essas organizações busquem estratégias de novos modelos de gestão, melhorando os seus padrões para uma ação eficaz de melhoria da qualidade ambiental norteada pelo embasamento sistêmico para um desenvolvimento viável.

Segundo Katz e Kahn ( apud CURY, 2006, p. 118):

A organização, como sistema, tem uma produção, um resultado ou um produto, mas este, no entanto, não é necessariamente idêntico às finalidades individuais dos membros dos grupos. (...) As organizações sociais são flagrantemente sistemas abertos, porque o insumo de energias e a convenção do produto em novo insumo de energia consistem em transações entre a organização e seu meio ambiente. 
Portanto, nas mais diversas atividades desenvolvidas pelo homem, individualmente e/ou de forma coletiva nas organizações, não se pode deixar de considerar o meio ambiente, pois dele são extraídos os recursos naturais para produção e posteriormente são devolvidos em formas de produtos, serviços e resíduos sólidos. Nesse ciclo, o uso dos recursos naturais vem crescendo de forma acelerada e por consequência causando ações negativas no meio ambiente e comprometendo o equilíbrio dos ecossistemas.

Para Vieira e Weber (2002, p.18), a crise contemporânea do meio ambiente é decorrente do progressivo esgotamento das várias abordagens de desenvolvimento e experimentos ao longo do tempo. Trata-se, também, de uma crise da atividade econômica e das instituições reguladoras, norteadas pelas contradições paradigmáticas da ideia de progresso e desenvolvimento seja sinônimo de dominação da natureza.

O aparecimento da gestão de recursos naturais como área de pesquisa se insere como um dos componentes fundamentais do processo de regulação das relações mútuas dos sistemas socioculturais e o meio ambiente biofísico. Articula-se numa dinâmica que compreende uma sequência de atividades interativas entre as práticas econômicas e as de conservação do meio ambiente.

Para nortear a gestão de recursos naturais, Vieira e Weber (2002) apresentam o modelo figura 1 , denominado a dinâmica dos modos de apropriação e gestão de recursos renováveis, que toma por base a aplicação de princípios e métodos da "pesquisa de sistemas complexos" (citando Von Bertalanffy, 1968; Jollivet, 1992; Simon, 1969; Ozbekhan, 1971; Ackoff, 1979; Sachs, 1986; Simmonis, 1984; entre outros). 
Figura 1 - Modelo compacto de análise GREEN

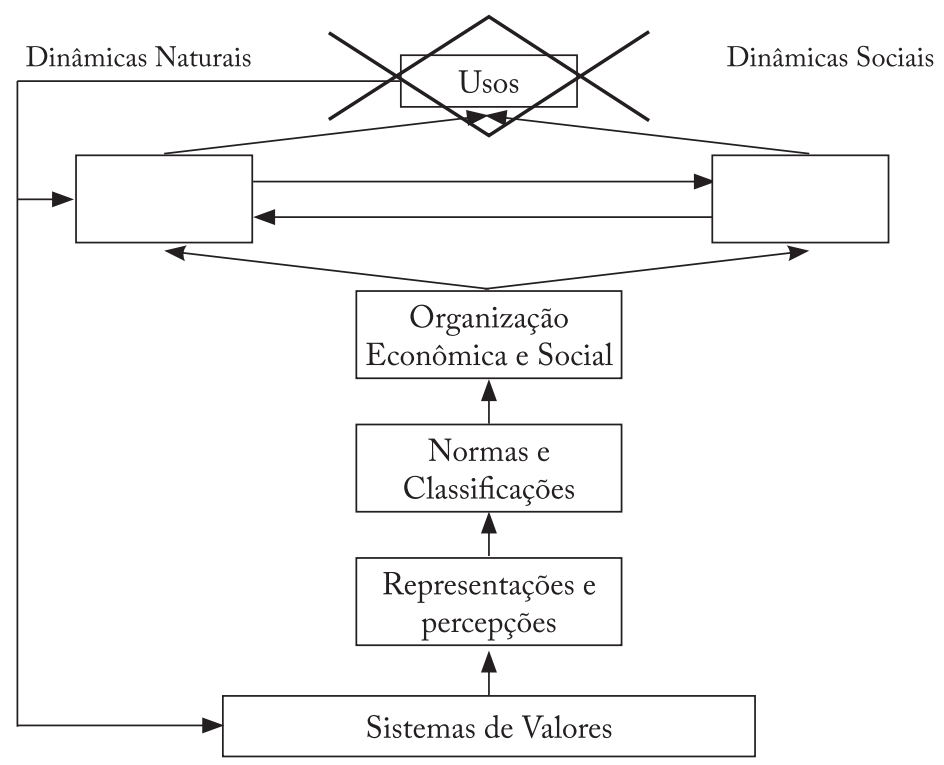

Fonte: Adaptado Vieira e Weber (2002).

O modelo de gestão proposto leva em conta os usos dos recursos naturais, no contexto das dinâmicas naturais e sociais, considerando que os mesmos se transformam com o passar dos anos, dependendo tanto da evolução dos processos naturais, como também da evolução da tecnologia. Para análise do modelo, têm-se as seguintes variáveis: modos de apropriação e processos decisórios; organização econômica e social; normas e classificações; representações e percepção e sistema de valores, que devem ser usadas em função do que é requerido de recursos naturais para atender as demandas das necessidades.

Como contribuição para entendimento conceitual de Modos de Apropriação, Vieira, Berkes e Seixas (2005) apresentam quatro tipos de regimes de apropriação que consideram ideais e tendem a ser controlados mediante a combinação entre eles: a) livre acesso - representa a ausência de direitos de propriedade bem definidos e, por conseguinte, incompatível com a sustentabilidade, em virtude da falta de normas e regulamentos; b) propriedade privada - refere-se à situação na qual um indivíduo ou corporação têm o direito de excluir outros e de regulamentar o uso do recurso que se apropriou; c) propriedade estatal - significa que os direitos sobre os recursos naturais, constituem prerrogativas exclusivas do governo, que controla o acesso e regulamenta o uso; d) 
propriedade comunal - neste tipo, o recurso é controlado por uma comunidade definida de usuários, que pode excluir outros usuários e regulamentar a sua a utilização.

Para Ollagnon (2002, p.183), a titularidade do patrimônio entendese como aquela que estabelece uma relação com elementos materiais e imateriais do seu meio ambiente e que cada ator social gera seu patrimônio através do envolvimento simultâneo com todas as categorias de titulares, sejam elas pessoa física, jurídica e comunidade.

Para os Processos Decisórios, Robbins (2000, p.65) apresenta as vantagens das decisões tomadas em grupo, partindo do princípio de que os grupos geram informações e conhecimentos mais completos, pois agregam conhecimentos de vários atores sociais, trazendo mais dados e heterogeneidade para o processo de decisão, além de oferecer maior diversidade de opiniões, abrindo a oportunidade para que mais abordagens e alternativas sejam consideradas.

A ênfase colocada na dimensão Organização, segundo Vieira e Weber (2002, p.19), estimula uma percepção renovada de possibilidade ainda pouco explorada de inovação social. Como importante variável do GREEN; na organização econômica e social, as mudanças de atitudes sobre o compartilhamento dos objetivos institucionais devem ser traduzidas no estabelecimento de metas que possam ser incorporadas e praticadas por todos que a integram, visando a alcançar os resultados desejáveis.

Duas propostas são apresentadas para nortear a gestão da inovação social: a primeira, política ambiental antecipativa-preventiva, cuja dimensão de longo prazo permite o seu aperfeiçoamento constante através das ações das pesquisas interdisciplinares e legitimação na esfera política. A segunda, política ambiental preventiva-adaptativa, cujo ponto de partida perpassa pela discussão sobre sistemas alternativos de valores sociopolíticos, análise da causas das crises de natureza global e o estabelecimento de indicadores sociais e ecológicos que apresentem resultados fidedignos da situação e possibilitem a construção e um novo modelo contratual de projetos de sociedade (VIEIRA; WEBER, 2002, p.19-20).

O Estado deve liderar as questões relacionadas com os recursos naturais, como instituição, deve estabelecer princípios norteadores para uso dos recursos naturais. Carvalho (2003, p. 281) afirma que: "o direito ao meio ambiente, chamado de 'direito de terceira geração', não impõe 
deveres apenas ao Estado, mas a todos, pessoas físicas ou jurídicas". Para Ollagnon (1990 apud Weber 2002, p. 29), uma concepção alternativa de regulação pode ser extraída do cenário que prevê a possibilidade de representação dos recursos transapropriativos mediante a categoria de patrimônio comum, a ser gerido em bases contratuais.

As Representações e Percepções se apresentam como contraponto aos paradigmas tradicionais de análise, o GREEN, focaliza prioritariamente os interesses do atores na gestão, posteriormente a figura do decisor. $\mathrm{O}$ modelo visa, dentre outros, a identificar as propostas das representações, nas quais emergem objetivos estratégicos a serem compartilhados pelos atores sociais antes do processo de estruturação das possíveis soluções.

Para Sistemas de Valores, Ferreira (2004, p.2033) interpreta que valores são "as normas, princípios ou padrões sociais aceitos ou mantidos por indivíduo, classe, sociedade”. Sendo assim, as decisões são tomadas e ao fazê-las, invocam-se os valores presentes no cotidiano, seja de forma consciente ou inconscientemente, portanto age-se mediante os valores individuais que se possui.

De acordo com Nadas (2002, p.1), a moral é a ordenação de valores, orientada ao posicionamento que se assume em função das tomadas de decisões, tendo esse posicionamento um fundamental papel na sociedade como um todo. Já a ética é a maneira de se pôr em prática os valores morais; um sistema de balizamento ou de codificação para ser usado na tomada de decisões.

\section{Responsabilidade Social e Gestão de Recursos Naturais}

A atual realidade da responsabilidade social das organizações é resultado das ações e procedimentos adotados pelas organizações desde 1721, quando o Conselho Econômico e Social da ONU, através de resolução, iniciou estudos sobre o papel e o efeito das multinacionais nos países emergentes, Rebouças (2009). Desde então, tem havido uma série de mudanças nas terminologias e, adicionalmente, a proliferação de várias abordagens.

Robert Owen, representante do socialismo utópico no princípio do século XIX, sócio da algodoaria New Lanark, na Escócia, propôs a criação de várias comunidades industriais para atender as pessoas que trabalhavam e viviam em péssimas condições de higiene e moradia, 
criou também um armazém em que se podiam comprar mercadorias a preço módico, além de estabelecer um rigoroso controle da venda de bebidas alcoólicas, o que resultou na redução dos vícios e de crimes. Em1816, ele fundou a primeira escola maternal britânica (DEC/ UFCG, 2011).

Em 1863, a Grã-Bretanha aprova a primeira lei contra poluição do mundo e cria o primeiro órgão de controle da poluição. Na Alemanha, em 1929, inaugura-se a ideia de "função social da propriedade". O aperfeiçoamento dos transportes no século XIX, mais do que o fácil acesso à informação da segunda metade do século XX, disseminou o conhecimento sobre as condições do meio ambiente. Mais pessoas puderam ver o que acontecia com os recursos naturais em um espaço maior que os arredores de sua comunidade.

Aos poucos, com os questionamentos de ativistas sociais com relação à prática de discriminação das minorias, dos objetivos econômicos únicos das empresas privadas e suas ações danosas ao meio ambiente, tornam-se crescentes as ideias de intervenção do Estado, como também as exigências de tomada de decisão com base nos aspectos sociais no que se refere à: filantropia; determinação de preços; relações com os funcionários; preservação dos recursos; qualidade de produtos e operações em países que violam os diretos humanos.

As expectativas intervencionistas não são bem vistas pelas indústrias americanas, especialmente frente ao papel desempenhado pelas empresas nos Estados Unidos, cuja filosofia econômica predominante é de que o governo não deveria interferir nos negócios e que a liberdade de mercado entre oferta e demanda resultaria no uso responsável dos recursos naturais, e o contínuo crescimento econômico asseguraria o bem-estar das pessoas.

Para reforçar ainda mais as correntes de defesa da intervenção do Estado, Upton Sinclair publicou, em 1906, o romance The Jungle (a Selva), onde narrava a realidade da indústria da carne, que segundo Sinclair, (apud SOUZA, 1996. p. 52), "A carne misturada com pedaços de tecidos esfarrapados e sujos, pães mofados, moídos juntamente com os enchimentos das lingüiças eram vendidas em Chicago, embora proibidas no comércio exterior", resultando na Lei Comida Pura.

Diante da evolução da ideia de responsabilidade social das empresas, alguns estudiosos relatavam paralelamente suas impressões de que cabia ao governo, igrejas, sindicatos e organizações não-governamentais 
o suprimento das necessidades comunitárias através de ações sociais organizadas e não às empresas, que na verdade precisavam satisfazer seus acionistas.

Para Cruz (2006, p.13), "responsabilidade social é um conceito amplo, com muitos significados e sinônimos: cidadania corporativa, desenvolvimento sustentável, crescimento sustentável, sustentabilidade, capitalismo sustentável, filantropia empresarial, marketing social, ativismo social empresarial”. Já para Melo Neto (1999, p.78), “responsabilidade social de uma empresa consiste na sua decisão de participar mais diretamente das ações comunitárias na região em que está presente e minorar possíveis danos ambientais decorrentes do tipo de atividade que exerce"

Segundo Garrida e Melé (2004, p.3), as teorias e os enfoques mais importantes da Responsabilidade Social Corporativa (RSC) estão presentes em quatro dimensões relacionadas com benefícios, atuação política, demanda social e valores éticos. Esses enfoques permitem uma discussão das teorias em quatro grupos: instrumentais, políticas, integradoras e éticas. As teorias instrumentais abordam a empresa exclusivamente como instrumento de criação de riqueza e suas atividades sociais são usadas como meio para alcançar a lucratividade. As teorias políticas fazem referências ao poder das empresas nas sociedades e suas responsabilidades no cenário político. As teorias integradoras que abordam as empresas como centro da captação, identificação e respostas as demandas sociais. Com esse elo, pretende a legitimação social e maior ascensão e prestígio social. As teorias éticas referenciam-se nas responsabilidades éticas das empresas para com a sociedade, baseadas em princípios que expressam na necessidade da construção de uma sociedade melhor.

Nas suas ações, o Instituto Ethos (2009) busca disseminar a prática de responsabilidade social no ambiente organizacional, caracterizando a ação socialmente responsável da seguinte forma: Responsabilidade Social Empresarial (RSE) é a forma de gestão que se define pela relação ética e transparente da empresa com todos os públicos com os quais ela se relaciona e pelo estabelecimento de metas empresariais que impulsionem o desenvolvimento sustentável da sociedade, preservando recursos ambientais e culturais para as gerações futuras, respeitando a diversidade e promovendo a redução das desigualdades sociais.

Entretanto, mesmo não existindo unanimidade na definição do termo, deve-se adotar nas organizações um significado que se refere às decisões tomadas nos negócios norteadas por valores éticos, legais, 
respeito às pessoas, comunidades e meio ambiente. Assim, o desempenho das organizações, nesse contexto, deve estar associado a uma posição ativa e inovadora, para enfrentar os desafios crescentes como organismo de desenvolvimento e bem-estar social.

Reconhecer os benefícios das práticas de responsabilidade social tem sido o enfoque das abordagens de muitos autores, embora com visões diferentes. Para Carrol (1991, p.2), a concepção de Responsabilidade Social Empresarial (RSE) é concebida em quatro tipos de responsabilidade: econômica, legal, ética e discricionária ou filantrópica. A responsabilidade econômica relaciona-se pelo objetivo com que foram criadas, ou seja, como entidades econômicas destinadas a fornecer bens e serviços aos membros da sociedade. O lucro foi estabelecido como o incentivo primário para o empreendedorismo. $\mathrm{Na}$ responsabilidade legal, espera-se respeito às leis e regulamentos promulgados pelo poder público municipal, estadual e federal. Essa responsabilidade reflete uma visão de "ética codificada" no sentido de que incorporam as noções básicas das operações estabelecidas pelos nossos legisladores. A ética, como outro tipo de responsabilidade, incorpora as normas ou expectativas que refletem uma preocupação com os consumidores, colaboradores, acionistas e comunidade, em consonância com o respeito ou a proteção dos direitos e valores morais. A responsabilidade filantrópica inclui uma participação mais ativa em atos ou programas para promover o bem-estar humano. A figura 2 apresenta este modelo, onde as responsabilidades são ordenadas da base para o topo em função de sua magnitude relativa e da frequência dentro das quais, os gestores lidam com cada aspecto.

Figura 2 - Os quatro tipos de responsabilidade social:

Total Responsabilidade Social Empresarial

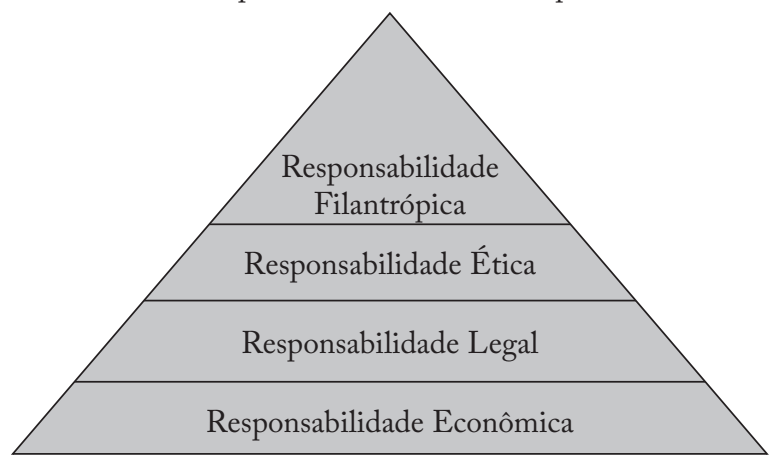

Fonte: Carroll (1991). 
Nesta abordagem, os seguintes pressupostos anteriormente relatados são definidos como seguem:

1. A responsabilidade econômica relaciona-se pelo objetivo com que foram criadas, ou seja, como entidades econômicas destinadas a produzir bens e serviços de que a sociedade necessita e quer, a um preço que possa garantir a continuação das atividades da empresa, de forma a satisfazer suas obrigações com os investidores e maximizar os lucros para os seus proprietários e acionistas.

2. Responsabilidade legal define o que a sociedade considera importante com respeito ao comportamento adequado da empresa. Ou seja, esperam-se das empresas que atendam às metas econômicas dentro da estrutura legal e das exigências legais, que são impostas pelos conselhos locais das cidades, assembleias legislativas estaduais e agências de regulamentação do governo federal.

3. Responsabilidade ética inclui comportamentos ou atividades que a sociedade espera das empresas, mas que não são necessariamente codificados na lei e podem não servir aos interesses econômicos diretos da empresa. O comportamento antiético, que ocorre quando decisões permitem a um indivíduo ou empresa obter ganhos à custa da sociedade, deve ser eliminado. Para serem éticos, os tomadores de decisão das empresas devem agir com equidade, justiça e imparcialidade, além de respeitarem os direitos individuais.

4. Responsabilidade discricionária ou filantrópica é puramente voluntária e orientada pelo desejo da empresa em fazer uma contribuição social sem ser imposta pela economia, pela lei ou pela ética. A atividade discricionária inclui: fazer doações a obras beneficentes; contribuir financeiramente para projetos comunitários ou para instituições de caridade que não oferecem retornos para a empresa e nem mesmo são esperados.

Considerando as questões abordadas, o empresário Oded Grajew criou, em 1998, o Instituto Ethos de Empresas e Responsabilidade Social, que objetiva disseminar a prática social através de publicações, experiências vivenciadas, programas e eventos para seus associados e interessados em geral, procurando contribuir para o desenvolvimento social, econômico e ambiental de uma nova cultura empresarial baseada na ética, nos princípios e valores. 
Grajew (2000, p.31) afirma que:

As empresas e seus líderes têm um papel fundamental diante deste cenário. Em poder das corporações, está o capital, a capacidade de gestão dos recursos e, sobretudo, um extraordinário estoque de talentos, fator decisivo em qualquer processo de transformação. Para desempenhar esse papel, é preciso que o mundo corporativo siga alguns princípios elementares. Em primeiro lugar, é urgente tomar consciência da realidade que nos rodeia e do fato de que fazemos parte dela. Em seguida, é preciso entender o conceito de responsabilidade social como o compromisso de cada um com a qualidade de vida, com a preservação da natureza e com uma sociedade mais justa.

Nessa perspectiva, a aplicação dos conceitos referentes à responsabilidade social conduz a organização a uma nova abordagem de gestão, estabelecendo relações a partir de valores e condutas, como também, sendo capaz de satisfazer necessidades e interesses dos seus parceiros internos e externos. Desta forma, o que se espera de uma organização realmente preocupada na solução dos problemas da sociedade, é a responsabilidade social como uma política institucional que envolva e comprometa todos os atores sociais da organização.

Não se pode deixar de considerar, entretanto, outras possíveis definições que geram novos quadros de modelos conceituais, particularmente aqueles associados à responsabilidade social que tratam das relações éticas e morais das organizações. Nesse caso, como se trata de questões muito subjetivas, são desenvolvidos modelos teóricos que objetivam alinhar o comportamento da organização, de modo a permitir a visualização do estágio em que se encontra.

Para Ashley (2003, p.6), o termo responsabilidade social pode ser definido como:

O compromisso que a organização deve ter com a sociedade, expresso por meio de atos e atitudes que afetem positivamente, de modo amplo, ou a alguma comunidade, de modo específico, agindo proativamente e corretamente no que tange a seu papel específico na sociedade e a sua prestação de contas para com ela. 
A partir do modelo tridimensional de RSE desenvolvido por David Wood, Ashley (2003 apud Santos, 2007) construiu um novo modelo chamado Análise do Conteúdo da Comunicação de Estratégias de Responsabilidade Social Empresarial - ACCERSE; no qual, proporciona conhecer como as ações de responsabilidade social empresarial (RSE) são estabelecidas nas organizações. O resultado é obtido através da observação da comunicação empresarial. O referido modelo objetiva analisar como se processa a comunicação da estratégia relacionada com RSE, o qual é agrupado em quatro temas assim distribuídos:

1. Princípios e Diretrizes: trata do tema relacionado com a difusão dos valores da RSE e regras de gestão que norteiam a conceituação da RSE e como é entendida pela organização;

2. Processos Organizacionais: este tema é indicado para acompanhar a forma como a organização incorpora os princípios e diretrizes da RSE na rotina do dia a dia;

3. Projetos e ações Específicas: objetiva explicar como as políticas e programas da organização estão relacionados diretamente a RSE;

4. Transparência e Publicidade: temática mais relevante no processo de comunicação e conhecimento dos assuntos relativos à RSE.

5. Nessa visão, observa-se que o modelo Ashley de RSE tem um caráter institucional e que pode ser trabalhado em instituições públicas, privadas e especialmente na proposta de gestão de recursos naturais. É importante entender que os atores sociais são chamados a refletir sobre novos conceitos e modelos de gestão que são desenvolvidos e que colocam como possibilidade resguardar a preservação ambiental e as melhorias dos processos voltados para o desenvolvimento sustentável.

Para que essas diretrizes e ações de Responsabilidade Social sejam concretizadas é necessário que as organizações se comprometam de maneira diferenciada com a construção de um novo paradigma de gestão, especialmente no que se refere à construção da cidadania, tornando-os sensíveis aos problemas sociais que os rodeiam. Isto será possível na medida em que as práticas de gestão, bem como a participação dos atores sociais estejam comprometidas com a construção de iniciativas de responsabilidade social. 
Essas mudanças devem estar alinhadas com a organização de forma sistêmica no processo de modernização e no estabelecimento de critério valorativo para o desenvolvimento organizacional, analisando-se, então, suas estruturas básicas, seus processos de trabalho e sua missão: no contexto social e no significado da organização em todos os níveis. A implantação de ações relacionadas com novas práticas, processos, sistemas e atividades de forma contínua são irreversíveis nas organizações, implicando, portanto, na criação de uma cultura própria, envolvendo não apenas novas relações com a sociedade, mas também novas formas de interação internas e novas relações de poder.

\section{A interface entre Responsabilidade Social e a Gestão de Recursos Naturais}

De acordo, com descrição do modelo GREEN, no contexto da gestão de recursos naturais e da responsabilidade social, identifica-se os pressupostos considerados no estudo sobre a interface da responsabilidade social na gestão de recursos naturais. A maioria das definições apresentadas sobre responsabilidade social reforça a ideia de que a ética, a cultura e os valores morais são inseparáveis de qualquer noção de responsabilidade social, mesmo considerando que no caso específico do modelo GREEN, o sistema de valores ainda não seja representativo, frente às demais variáveis.

De acordo com Ashley (2003, p.51), os valores morais dizem respeito a crenças pessoais sobre comportamento eticamente correto ou incorreto, tanto por parte do próprio individuo quanto com relação aos outros. A moral pode ser vista como um conjunto de valores e de regras, comportamentos que as coletividades, sejam elas nações, grupos sociais ou organizações, adotam por julgarem corretos e desejáveis.

Os valores são a forma de resolver as dúvidas dos atores sociais a respeito do modo de conduta em determinadas situações, quer seja porque a situação em si não deixa claro qual é a conduta a ser seguida, ou o desejo do individuo vai numa direção oposta às regras ou às pressões sociais, e as sanções sociais por ignorá-las ou transgredi-las seriam mais fortes (PEREIRA, 2006, p.18).

Os valores éticos, conforme Carroll (1991), assumem uma importância significativa que é vista como outra responsabilidade, pois incorpora as normas ou expectativa, as quais vão refletir na preocupação com os consumidores, colaboradores, acionistas e comunidade. 
Assim observa-se que os valores podem ser definidos como crenças e pressupostos básicos de uma organização, possuindo atributos de conteúdo e de intensidade. Os atributos de conteúdo determinam o modo de conduta ou de valores finais e os atributos de intensidade correspondem ao quanto ele é importante.

Nesse contexto, a gestão de recursos naturais incorpora no sistema de valores os pressupostos da responsabilidade social no que se refere às obrigações da organização seja ela econômica ou social, mas que terá de estabelecer normas e regulamentos que possam classificar e ordenar o uso dos recursos naturais, modos de apropriação e os processos decisórios.

A abordagem da gestão de recursos naturais resultante desse estudo tem a responsabilidade social como instrumento norteador para as variáveis: sistema de valores; representações e percepções; normas e classificações: organização econômica e social; modos de apropriação; processos decisórios e usos dos recursos, como estão expostos na figura 3.

Figura 3 - Modelo compacto de análise GREEN.

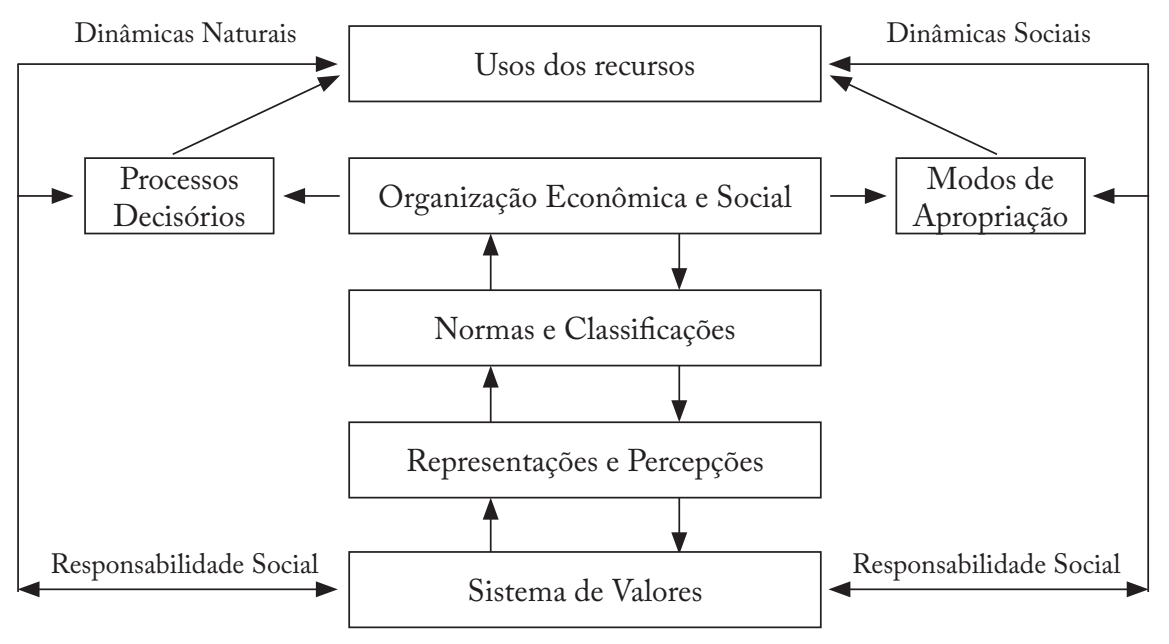

Fonte: Adaptado pelo autor (2011)

O Sistema de Valores é o condicionante mais importante dentro desse contexto, pois dele são norteadas as formas de condutas, metas e ações dos indivíduos e das organizações. É nesta variável, que a interface da responsabilidade social se incorpora à gestão de recursos naturais, na perspectiva de uma interação social e nos requisitos para a sobrevivência dos grupos. 
As Representações e Percepções dos atores sociais estão sob a influência do sistema de valores e buscam uma nova forma de compreender o uso dos recursos naturais, ao mesmo tempo em que provocam alteração no comportamento e nas atitudes em relação à participação e à responsabilidade na gestão compartilhada.

Ao se definir as Normas e Classificações como processo regulador nas ações de uso dos recursos naturais, estas expressam o paradigma vigente na gestão e servem como instrumento para o planejamento. Para Pereira (2006), as normas são expectativas transformadas em exigências e juntamente com os valores são elementos de integração, uma vez que todos os praticam.

A Organização Econômica e Social é o espaço social, onde as pessoas interagem no sentido de gerir os recursos para produzir resultados. Portanto, pode-se afirmar que nenhuma organização sobrevive se não atende adequadamente ao meio ambiente a qual está inserida. Pereira (2006, p.25). "As organizações expressam seus valores de diversas formas: em seus estatutos, nas reuniões dos conselhos diretivos, em suas publicações, nas declarações públicas de seus representantes, em seus sítios na Internet”.

O processo decisório no modelo do GREEN se contrasta com os paradigmas tradicionais de análise, pois focaliza os interesses dos atores sociais na dinâmica da gestão. Os pressupostos do sistema de valores são imperativos na formulação de políticas de longo prazo.

Segundo Ollagnon (2002), a titularidade do patrimônio é compreendida como o estabelecimento de uma relação com elementos materiais e imateriais do seu meio ambiente e que cada ator social gera seu patrimônio através do envolvimento simultâneo com todas as categorias de titulares, sejam elas pessoa física, jurídica e comunidade.

\section{Considerações finais}

Pode-se concluir que a maioria das definições de responsabilidade social e organização e gestão estão focadas na contemporaneidade em que a sociedade e as organizações estão inseridas. Essas considerações reforçam as tendências de gestão que apontam para uma necessidade de uma visão interdisciplinar que garanta o bom funcionamento dos sistemas de gestão, com participação ativa dos atores sociais, norteados por um sistema de valores. 
Como objetivo proposto, neste trabalho, foi ensaio teórico evidenciando a responsabilidade social na gestão de recursos naturais, considera-se que o mesmo tenha sido atendido, pelo fato de ter sido abordada a importância dos valores morais e éticos no funcionamento de um sistema de gestão, as organizações como fontes aglutinadoras de pessoas em busca de soluções de problemas e, por fim, a melhoria da qualidade da gestão de recursos naturais, em decorrência da inclusão de novos métodos de gestão com base na responsabilidade social.

Portanto, pode-se afirmar que a interface da responsabilidade social na gestão de recursos naturais está centrada no sistema de valores que norteia os indivíduos e as organizações. 


\section{Referências}

ASHLEY, Patricia Almeida. Ética e responsabilidade social nos Negócios. São Paulo: Saraiva, 2003.

BUSINESS SOCIAL RESPONSIBILITY (BSR). Business Brief:

Intangibles and CSR: Disponível: www.bsr.org/research/. Acesso em: 02, outubro, 2009.

CARROL, B. Archie. The Pyramid of Corporate Social Responsibility: toward the moral management of organizational stakeholders, Business Horizons, July-August 1991.

CARVALHO, A. Victor de. Responsabilidade penal por danos ambientais. In.: JÚNIOR, J. S. GALVÃO, Fernando. Direito Ambiental: na visão da magistratura e do Ministério Público. Belo Horizonte, MG. Del Rey, 2003. $616 \mathrm{p}$.

CRUZ, Lucia Maria Marcellino de Santa, Responsabilidade social Visão e intermediação da mídia na redefinição do público e do privado. Dissertação (Mestrado em Comunicação e Cultura) - Programa de Pós-Graduação em Comunicação e Cultura, Escola de Comunicação, Universidade Federal do Rio de Janeiro. 2006

CURY, Antonio. Organização e métodos: uma visão holística. $8^{0}$ ed. São Paulo: Atlas, 2006.

EGRI, Carolyn P.; PINFIELD, Laerence T. As organizações e a biosfera: ecologia e meio ambiente. In Handebook de estudos organizacionais. São Paulo: Atlas, 1998.

FERREIA, A. B. H. Novo dicionário Aurélio da língua portuguesa. 3. ed. Curitiba: Positivo, 2004.

GARRIGA, Elisabet; MELÉ, Domènec. "Corporate Social Responsibility Theories: Mapping the Territory”, Journal of Business Ethics, v.53, p.5171, 2004. 
GRAJEW, Oded. Somos todos responsáveis. Revista Exame, São Paulo, ed. 728, p. 31, 2000. Caderno especial: "Guia de Boa Cidadania Corporativa”.

INSTITUTO ETHOS. Disponível em: <http// www.ethos.org.br.> Acesso em: 13 out. 2009.

NADAS, Peter. Ética na administração: responsabilidade social do administrador. Fórum de responsabilidade e balanço social. São Paulo: SESI, 2002.

OLLAGNON, Henry. Estratégia patrimonial para a gestão dos recursos e dos meios naturais. Enfoque integrado da gestão do meio rural. In: VIEIRA, Paulo Freire e WEBER, Jaques. Gestão de Recursos Naturais Renováveis e Desenvolvimento: Novos Desafios para a Pesquisa Ambiental. São Paulo: Cortez, 2002.

GODARD, Olivier. A gestão integrada dos recursos naturais e do meio ambiente: conceitos, instituições e desafios de legitimação In: VIEIRA, Paulo Freire e WEBER, Jaques. Gestão de Recursos Naturais Renováveis e Desenvolvimento: Novos Desafios para a Pesquisa Ambiental. São Paulo: Cortez, 2002.

OWEN, Robert Disponível em: <http://www.dec.ufcg.edu.br/biografias / Robert Owe.htm> Acesso em: 09 mar. 2011. Parte superior do formulário.

PEREIRA, Edson Luiz. Valores individuais e valores organizacionais: uma contribuição para o estudo de congruências. 2006. 134 f. Dissertação (Mestrado em [Religião]) - Programa de Pós-Graduação da Universidade Presbiteriana Mackenzie. São Paulo. 2006.

REBOUÇAS, Fernando. Responsabilidade Socioambiental. Disponível em: $<$ http:/www.infoescola.com/sociedade/responsabilidade_socioambiental >. Acesso em: 09 mar. 2011.

ROBBINS, Stephen Paul. Administração: mudanças e perspectivas. São Paulo: Saraiva, 2000.

SANTOS, Raul César Mello dos. A responsabilidade social empresarial, uma questão de cultura: o caso PETROBRAS. Rio de Janeiro, 2007. 
SOUZA, Miriam de Almeida. A Política legislativa do Consumidor no Direito Comparado. Belo Horizonte: Edições Ciência Jurídica, 1996.

VIEIRA, Paulo Freire.; WEBER, Jaques. Introdução Geral: sociedade, natureza e desenvolvimento viável. In: VIEIRA, Paulo Freire.; WEBER, Jaques. Gestão de recursos naturais renováveis e desenvolvimento: novos desafios para a pesquisa ambiental. São Paulo: Cortez, 2002.

VIEIRA, Paulo Freire; BERKES, Fikret; SEIXAS Cristiana S. Gestão Integrada e Participativa de Recursos Naturais: conceitos, métodos e experiências. Florianópolis: APED, 2005. 